Bange, Jens ; Beyrich, Frank ; Engelbart, Dirk A. M.

\begin{abstract}
Airborne measurements of turbulent fluxes during LITFASS98: Comparison with ground measurements and remote sensing in a case study
\end{abstract}

URL: http://www.digibib.tu-bs.de/?docid=00015766

Zuerst erschienen in:

Theoretical and Applied Climatology, Springer Wien, 73(2002), S. 35 - 51 The original publication is available at www.springerlink.com. DOI: $10.1007 / \mathrm{s} 00704-002-0692-6$

http://springerlink.metapress.com/content/efvy70qunpawvlk5/fulltext.pdf

HINWEIS:

Dieser elektronische Text wird hier nicht in der offiziellen Form wiedergegeben, in der er in der Originalversion erschienen ist. Es gibt keine inhaltlichen Unterschiede zwischen den beiden Erscheinungsformen des Aufsatzes, es kann aber Unterschiede in den Zeilen- und Seitenumbrüchen geben. 
Theor. Appl. Climatol. 73, 35-51 (2002)

DOI 10.1007/s00704-002-0692-6

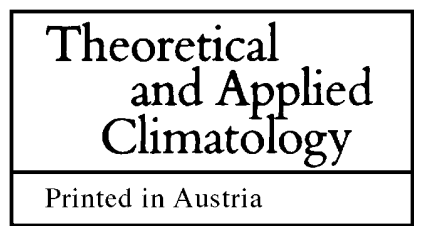

${ }^{1}$ Aerospace Systems, Technical University of Braunschweig, Germany

${ }^{2}$ Meteorological Observatory Lindenberg German Meteorological Service, Lindenberg, Germany

\title{
Airborne measurements of turbulent fluxes during LITFASS-98: Comparison with ground measurements and remote sensing in a case study
}

\author{
J. Bange ${ }^{1}$, F. Beyrich ${ }^{2}$, and D. A. M. Engelbart ${ }^{2}$ \\ With 14 Figures \\ Received June 18, 2001; revised December 21, 2001; accepted June 3, 2002 \\ Published online November 19, 2002 (C) Springer-Verlag 2002
}

\begin{abstract}
Summary
Simultaneous flight measurements with the research aircraft Do 128 and the helicopter-borne turbulence probe Helipod were performed on 18 June 1998 during the LITFASS-98 field experiment. The area-averaged turbulent vertical fluxes of momentum, sensible, and latent heat were determined on a $15 \mathrm{~km} \times 15 \mathrm{~km}$ and a $10 \mathrm{~km} \times 10 \mathrm{~km}$ flight pattern, respectively. The flights were carried out over heterogeneous terrain at different altitudes within a moderately convective boundary layer with Cumulus clouds.

Co-spectra-analysis demonstrated that the small scale turbulent transport was completely sampled, while the comparatively small flight patterns were possibly of critical size regarding the large-scale turbulence. The phygoide of the airplane was identified as a significant peak in some cospectra. The turbulent fluxes of momentum and sensible heat at $80 \mathrm{~m}$ above the ground showed systematic dependence on the location of the flight legs above the heterogeneous terrain. This was not observed for the latent heat flux, probably due to the vertical distribution of humidity in the boundary layer.

Statistical error analysis of the fluxes $F$ showed that the systematic statistical error $\Delta F$ was one order of magnitude smaller than the standard deviation $\sigma_{F}$. The difference between area-averaged fluxes derived from simultaneous Helipod and Do 128 measurements was much smaller than $\sigma_{F}$, indicating that the systematic statistical error was possibly over-estimated by the usual method.

In the upper half of the boundary layer the airborne-measured sensible heat flux agreed well with windprofiler/RASS data. A linear fit was the best approximation for the height
\end{abstract}

dependence of all three fluxes. The linear extrapolations of the latent and sensible heat fluxes to the ground were in good agreement with tower, scintillometer, and averaged groundstation measurements on various surface types. Systematic discrepancies between airborne and ground-based measurements were not found.

\section{Introduction}

Airborne measurements of meteorological parameters within the planetary boundary layer are of great interest for investigating the water and energy balance between the surface and the atmosphere as well as for parameterization and modeling exchange processes. A present-day research topic is the development of turbulent flux estimation methods for heterogeneous terrain. In this context, representative spatial data from aircraft measurements are a valuable standard of comparison for the results of averaging strategies from ground-based observations - at least on exemplary days. With this intention a one-day flight experiment was performed near the Meteorological Observatory Lindenberg (MOL) on 18 June 1998, complementary to the ground-based measurements carried out during the LITFASS-98 experiment. A description of the LITFASS project 
(Lindenberg Inhomogeneous Terrain - Fluxes between Atmosphere and Surface: a Long-Term Study) is given by Beyrich et al. (2002b). The main objective of airborne observations in LITFASS-98 was to complement ground-station measurements, remote sensing results, and numerical models with spatially representative data measured over the LITFASS site, a heterogeneous terrain typical of northern Central Europe.

Since aircraft travel over large distances in a comparatively short time, airborne measurements take a 'snapshot' of the atmospheric flow. Above a certain blending height (Claussen, 1991) the explicit influence of local surface characteristics disappears, and airborne measurements spatially integrate atmospheric parameters. The integration of a large amount of airborne point measurements sampled on a two-dimensional flight track leads to mean values of meteorological parameters. These may be interpreted as spatially representative, valid for the duration of the flight and for the surrounding area. The main aim of the analysis presented here was to determine area-averaged turbulent surface energy fluxes from flight measurements and to compare the results with ground-based observations above various surface types.

To determine turbulent surface fluxes from airborne measurements, a three-dimensional flight pattern (3D-box pattern) is usually used (e.g., Scherf and Roth, 1997; Grunwald et al., 1998; Schröter et al., 2000). This pattern consists of horizontal, square-shaped flight tracks at different altitudes within the boundary layer. The mean turbulent fluxes determined at each height are extrapolated to the ground in order to evaluate the surface flux. This method is generally useful in stationary situations if a linear flux profile can be assumed. Unfortunately, systematic differences between ground-based and airborne measurements have often been reported and lessen the reliability of airborne flux measurements (Desjardins et al., 1989; André et al., 1990; Betts et al., 1990; Betts et al., 1992; Kelly et al., 1992; Mahrt and Ek, 1993; Mann and Lenschow, 1994; Emeis, 1995; Grunwald et al., 1996). In most cases the discrepancies were explained with filter effects, spectral bandwidth of the airborne sensors, and too short flight tracks. To quantify the latter, a complex statistical error analysis has been introduced in several publications (e.g., Lumley and Panofsky, 1964; Lenschow and
Stankov, 1986; Lenschow et al., 1994). For the present measurements, parts of the error analysis were extracted and slightly modified. Filter effects and the bandwidth of measured turbulent fluxes were analyzed using co-spectra. To identify dependence of the measured fluxes on sensor equipment or flight distance, two different airborne turbulence measurement systems, the Do 128 'IBUF' and the Helipod, were used simultaneously on different flight patterns in LITFASS98. For the direct comparison, a special flight strategy was worked out that took the individual mission speeds of the two systems into account.

\section{Measurement equipment}

During the LITFASS-98 flight experiment the long-term operating systems at the MOL were complemented by two different airborne systems: the Do 128 research aircraft of the Technical University of Braunschweig, Germany, and the helicopter-borne system Helipod, at that time owned by the University of Hannover, Germany.

\subsection{Do 128}

The Do 128 with the call sign D-IBUF (Fig. 1) is a proven and very reliable meteorological research aircraft. For over ten years the system has participated in many meteorological campaigns. Technical descriptions are given by Hankers (1989) and Corsmeier et al. (2001). The twin-engined research aircraft operates at an airspeed of $60 \mathrm{~ms}^{-1}$ with an endurance up to five hours. The system was re-equipped in $1999 / 2000$ in order to achieve a higher sampling rate and to increase the accuracy of turbulence measurements (Brinkmann, 1999), though in LITFASS-98 the Do 128 still operated with its old equipment, briefly characterized in Table 1 . The sampling rate of $25 \mathrm{~Hz}$ led to a horizontal measurement-point distance $\Delta s$ of $2.4 \mathrm{~m}$. Humidity and temperature sensors were mounted at the nose of the aircraft. The wind vector was measured with a 5-hole probe on a $2.6 \mathrm{~m}$ noseboom in combination with GPS and INS on board. Taking the spatial arrangement of the sensors, the measurement-point distance $\Delta s$, and disturbing effects of fuselage and wings into account, the Do 128 could resolve turbulent structures down to $r_{\text {sys }}=5 \mathrm{~m}$. 


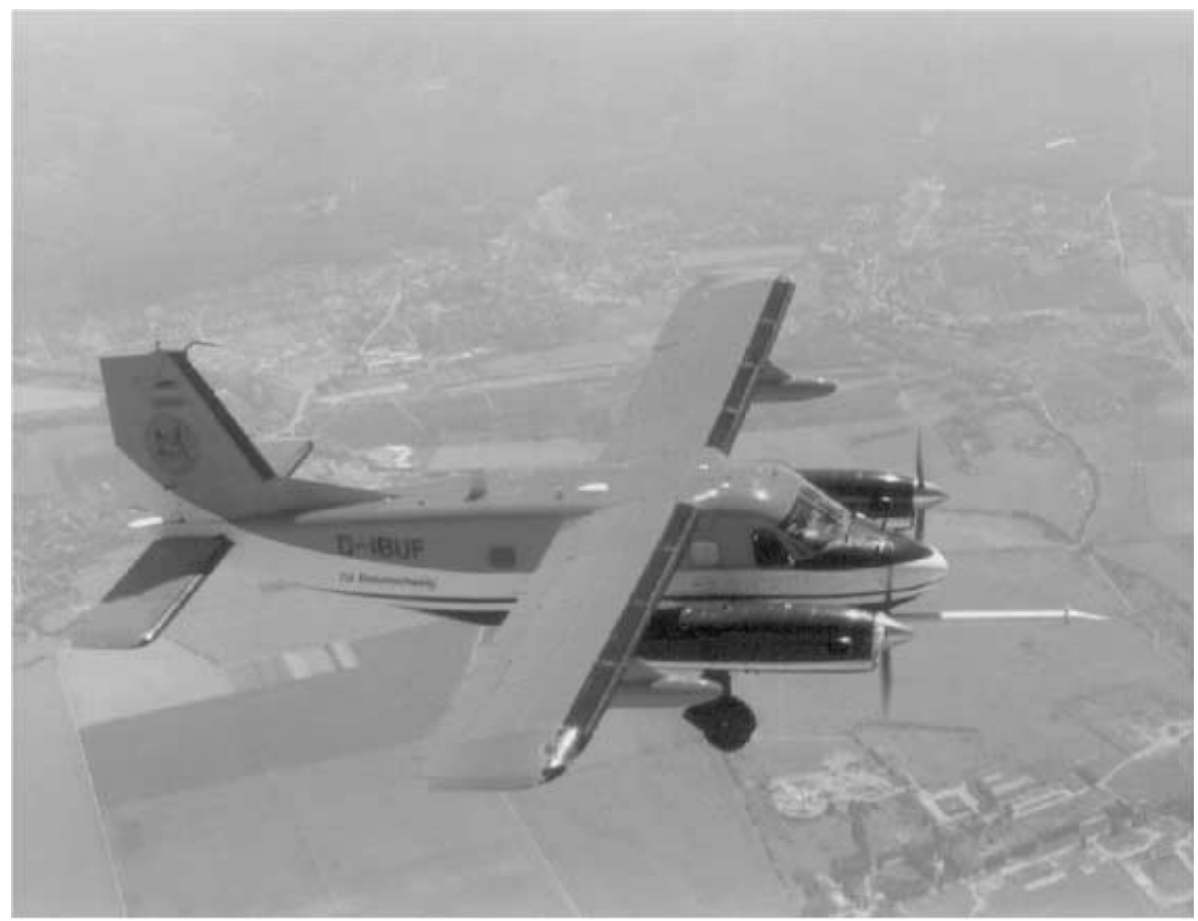

Fig. 1. The Do 128 research aircraft 'IBUF' (the photography was kindly made available by the Insitute for Flight Guidance, Technical University of Braunschweig)
Table 1. Technical comparison of the two airborne measurement systems in LITFASS-98

\begin{tabular}{|c|c|c|}
\hline & Do 128 & Helipod \\
\hline Mission air speed & $60 \mathrm{~m} / \mathrm{s}$ & $40 \mathrm{~m} / \mathrm{s}$ \\
\hline Sampling rate & $25 \mathrm{~Hz}$ & $100 \mathrm{~Hz}$ \\
\hline \multicolumn{3}{|l|}{ Wind vector } \\
\hline Ground speed & GPS, INS & 2 GPS, INS \\
\hline True air speed & $\begin{array}{l}\text { 5-hole probe } \\
\text { on nose-boom }\end{array}$ & 5-hole probe \\
\hline \multicolumn{3}{|l|}{ Temperature } \\
\hline Fast & $\begin{array}{l}\text { Pt-100 in } \\
\text { Rosemount } \\
\text { housing }\end{array}$ & open wire \\
\hline Slow & $\begin{array}{l}\text { Pt-100 in de-iced } \\
\text { Rosemount } \\
\text { housing }\end{array}$ & $\begin{array}{l}\text { Pt-100 in } \\
\text { Rosemount } \\
\text { housing }\end{array}$ \\
\hline \multicolumn{3}{|l|}{ Humidity } \\
\hline Fast & Lyman- $\alpha$ & Lyman- $\alpha$ \\
\hline Middle range & Humicap & Humicap \\
\hline Slow & dew-point mirror & dew-point mirror \\
\hline
\end{tabular}

\subsection{Helipod}

The Helipod is an autonomously operating sensor package attached to a $15 \mathrm{~m}$ rope below a helicopter of almost any type (Fig. 2). At a mission speed of $40 \mathrm{~ms}^{-1}$ the Helipod is outside the down-wash area of the rotor blades. The Helipod is equipped with its own power supply, on-board computer, data storage, navigation systems, radar altimeter, and fast responding sensors for wind, temperature, humidity, and surface temperature measurements (Table 1). All these instruments are installed in a container (pod) of $5 \mathrm{~m}$ in length and about $0.5 \mathrm{~m}$ in diameter. The fast inertial navigation and all meteorological sensors are concentrated in the nose of the pod. Due to the small fuselage, and absence of wings and impulse, the influence of the Helipod on the atmospheric flow is small compared to an airplane. Together with a sampling rate of $100 \mathrm{~Hz}$, the system resolves turbulent structures down to $r_{s y s} \leq 1 \mathrm{~m}$. Therefore it is particularly suited for small-scale turbulence measurements under thermally stable conditions (Bange and Roth, 1999). Further information about the system has been published in Bange (1997), Roth (1999), Wolff and Bange (2000), and Muschinski et al. (2000). Since 2001 the Helipod is owned by the Institute for Aerospace Systems at the Technical University of Braunschweig.

\subsection{Technical comparison of Helipod and Do 128}

Although both systems are similarly equipped for turbulence flux measurements, there are important differences between their measurement characteristics. The Do 128 is an airplane 


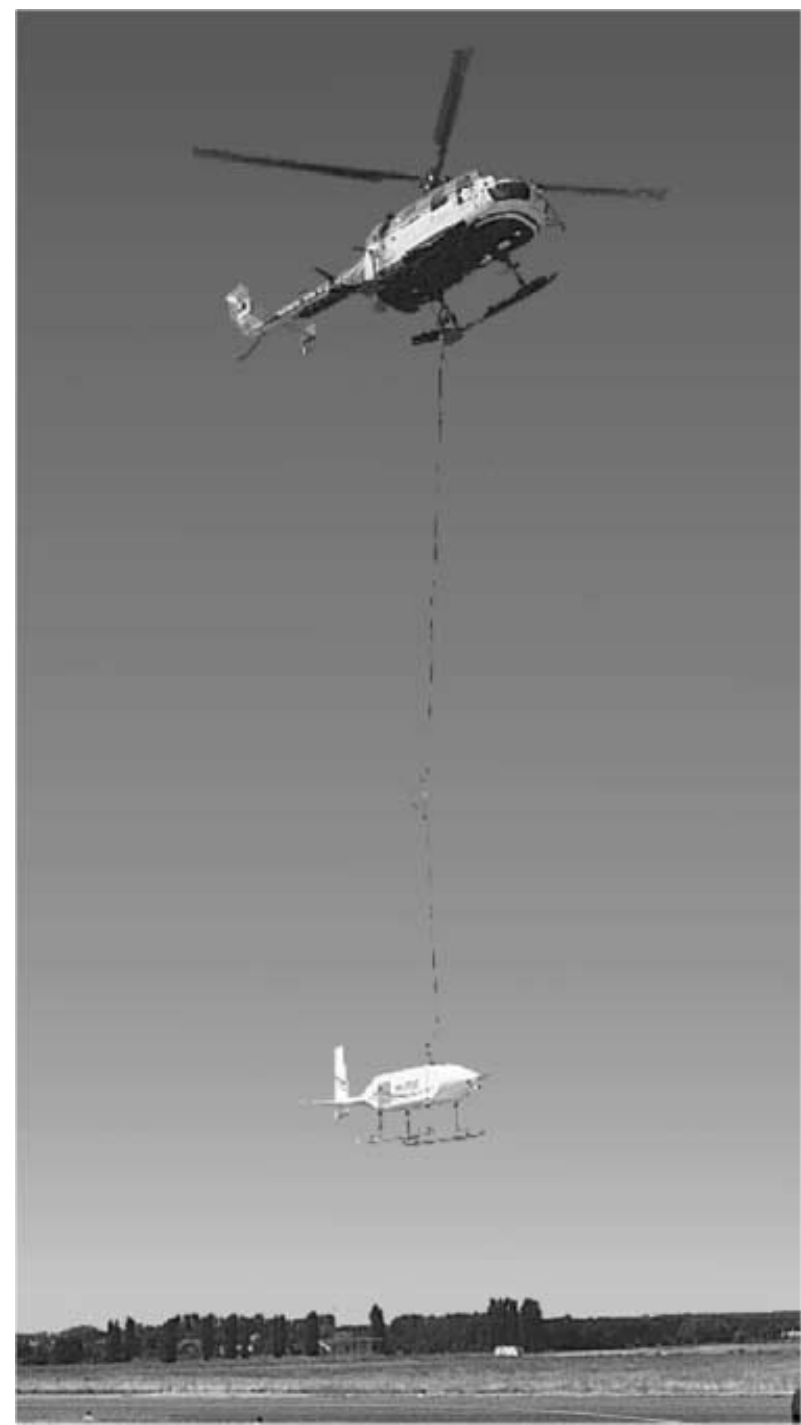

Fig. 2. The helicopter-borne turbulence measurement system Helipod

well suited for measurements in lower mesoscale and convective scale due to its long flight capacity. The Helipod operates at a higher sampling rate and lower air speed and is able to resolve small turbulence structures in the submeter range. Battery capacity and helicopter fuel limitations restrict its endurance to two hours, corresponding to a mission range of $280 \mathrm{~km}$. Since its first research flight in 1995 (Bange and Roth, 1999) the Helipod was mainly established in small-scale turbulent flows. One purpose of the present analysis was to determine whether the Helipod is suitable for convective situations as well.
Table 2. A selection of data available from ground-based measurement systems and windprofiler/RASS (WPR/ RASS) in LITFASS-98, relevant for the flight-measurement analysis: sensible heat flux $H$, latent heat flux $V$, momentum flux $\tau$

\begin{tabular}{|c|c|c|c|c|c|}
\hline System & Location & $\begin{array}{l}\text { Surface } \\
\text { type }\end{array}$ & $\begin{array}{l}\text { Altitude } \\
\text { in } \mathrm{m} \text { asl }\end{array}$ & $H$ & \\
\hline Tower & Falkenberg & grass & $\begin{array}{r}83 \\
103 \\
143 \\
163\end{array}$ & $\begin{array}{l}\bullet \\
\bullet \\
\bullet \\
\bullet\end{array}$ & • \\
\hline Scintillometer & $\begin{array}{l}\text { Falkenberg } \\
\text { Lindenberg }\end{array}$ & mixed & $73-93$ & $\bullet$ & \\
\hline Station & $\begin{array}{l}\text { Falkenberg } \\
\text { Lindenberg } \\
\text { Herzberg } \\
\text { Wulfersdorf } \\
\text { Kehrigk }\end{array}$ & $\begin{array}{l}\text { grass } \\
\text { barley } \\
\text { triticale } \\
\text { water } \\
\text { forest }\end{array}$ & $\begin{array}{l}73 \\
89 \\
90 \\
43 \\
49\end{array}$ & $\begin{array}{l}\bullet \\
\bullet \\
\bullet \\
\bullet \\
\bullet \\
\bullet\end{array}$ & $\begin{array}{l}\bullet \\
\bullet \\
\bullet \\
\bullet \\
\bullet \\
\bullet\end{array}$ \\
\hline WPR/RASS & Lindenberg & grass & & $\bullet$ & \\
\hline
\end{tabular}

\subsection{Ground-based measurements and remote sensing}

The airborne measurements were accompanied by ground-based observations along the eastern flight leg (see Fig. 2 in Beyrich et al., 2002b). The ground-based equipment consisted of five micro-meteorological stations over different surface types (grass, barley, water, forest, and triticale - the latter is a hybrid plant of wheat and rye), a $99 \mathrm{~m}$ meteorological tower equipped at four levels for turbulence measurements, and a large-aperture scintillometer measuring over $4.7 \mathrm{~km}$ distance between Lindenberg and Falkenberg. Characteristics and properties of these systems are described in this issue (Beyrich et al., 2002b). Furthermore, a SODAR/RASS (Engelbart et al., 1999) and a windprofiler/RASS system (Engelbart et al., 1996; Engelbart and Bange, 2001) were installed at Falkenberg and Lindenberg, respectively. Site characteristics and measured parameters of these systems relevant for the comparison to the airborne measurements are listed in Table 2.

\section{Methods}

\subsection{Experimental site}

The experimental area for the LITFASS-98 experiment was located near Lindenberg, a small 
village about $60 \mathrm{~km}$ southeast of Berlin. The flights covered approximately the Lindenberg grid cell of the 'Deutschlandmodell' (DM), the numerical weather prediction model of the German Meteorological Service (DWD) at that time. The investigation area was quite flat with a mean elevation of about $60 \mathrm{~m}$ above sea level (asl). The region consists of fields, coniferous forest, grassland, lakes, and some small settlements in between, as is typical for North-East Germany.

\subsection{Synoptic situation}

On the 18th of June, 1998, the weather in Northern Europe was determined by a low-pressure area over Scandinavia. Northern and Central Germany were under weak high pressure influence. A warm front approached from an East Atlantic low-pressure area and reached the experimental site two days later. Around 7:00 UTC (9:00 local time), when the flights started, $3 / 8$ Cumulus clouds at about $600 \mathrm{~m}$ height asl and complete cloud cover at high altitudes were observed. One hour later strong Cumulus development started at $800 \mathrm{~m}$ altitude. The cloud base rose up to $1200 \mathrm{~m}$ at around 10:30 UTC. Cumulus clouds covered about $5 / 8$ at that time. The aircraft and the helicopter observed light rain that did not reach the ground from around 10:45 UTC in the Lindenberg area.

The wind in the atmospheric boundary layer (ABL) came from the west. The wind speed varied between 2 and $5 \mathrm{~ms}^{-1}$ at the beginning of the experiment, and between 4 and $7 \mathrm{~ms}^{-1}$ later on. During the experiment, the temperature at the lowest flight levels of the Do 128 (245 $\mathrm{m}$ asl) rose from $10^{\circ} \mathrm{C}$ to $18^{\circ} \mathrm{C}$. The surface temperature measured by Helipod's infra-red radiometer was about $16^{\circ} \mathrm{C}$ at the beginning of the experiment.

\subsection{Flights}

\subsubsection{Horizontal flight patterns}

In order to determine area-averaged turbulent fluxes, the flights were performed in two 3Dboxes (Fig. 2 in Beyrich et al., 2002b). The inner 3 D-box $(10 \mathrm{~km} \times 10 \mathrm{~km})$ was flown by the Helipod, the outer one $(15 \mathrm{~km} \times 15 \mathrm{~km})$ by the Do 128. The horizontal dimensions of the boxes were chosen to meet the mission speed ratio of
Do $128\left(60 \mathrm{~ms}^{-1}\right)$ and Helipod $\left(40 \mathrm{~ms}^{-1}\right)$. For optimal comparison, flights of Do 128 and Helipod were performed simultaneously i.e., Do 128 and Helipod reached the corners of their flight patterns at the same time (see also Wolff and Bange, 2000). The turn at each corner was performed outside the box pattern. Only the linear flight segments (legs) were used for data analysis.

\subsubsection{Flight schedule}

Flight measurements started in the morning of 18 June 1998 (Table 3). The Do 128 airplane took off in Braunschweig airport and approached the experimental site at 6:30 UTC. After a first vertical sounding ('dtmp0') the Do 128 flew a single low level box ('dbox0') while the Helipod was prepared on the ground. At 7:05 UTC Do 128 and the helicopter met and performed a joint sounding. Because the helicopter was allowed to operate closer to the ground than the airplane, the lowest simultaneous boxes ('hbox1' and 'dbox1') were flown at different heights (see Table 3). The following two box flights ('hbox $2 / 3$ ' and 'dbox $2 / 3$ ') were then performed at identical levels and finished with another joint sounding.

Table 3. Time table, altitude, and names of Do 128 and Helipod flight measurements: Vertical soundings are indicated by 'tmp', horizontal measurement flights by 'box', 'h' stands for Helipod, 'd' for Do 128. Additional the measured (during vertical soundings) and the estimated (interpolated) $\mathrm{ABL}$ height $z_{i}$ is listed. The last column contains events and observations ( $\mathrm{Cu}$ : Cumulus clouds)

\begin{tabular}{llllll}
\hline $\begin{array}{l}\text { Start } \\
\text { time }\end{array}$ & Name & System & $\begin{array}{l}\text { Altitude } \\
\text { mTC (as) }\end{array}$ & $\begin{array}{l}z_{i} \\
\mathrm{~m}\end{array}$ & Comment \\
\hline 06:40 & dtmp0 & Do 128 & & 540 & \\
06:44 & dbox0 & Do 128 & 245 & 565 & \\
07:05 & dtmp1 & Do 128 & & 600 & meeting \\
& htmp1 & Helipod & & 600 & \\
07:18 & dbox1 & Do 128 & 245 & 670 & \\
& hbox1 & Helipod & 140 & 670 & \\
07:43 & dbox2 & Do 128 & 490 & 730 & \\
& hbox2 & Helipod & 490 & 730 & \\
08:08 & dbox3 & Do 128 & 760 & 805 & strong Cu \\
& & & & & develop. at \\
& & & & & $800 \mathrm{~m}$ \\
& hbox3 & Helipod & 760 & 805 & \\
08:33 & dtmp2 & Do 128 & & 840 & landing \\
& htmp2 & Helipod & & 840 & landing \\
\hline
\end{tabular}


Both systems finished the first experimental phase and landed. After re-fueling the Do 128 started again, while the Helipod remained at ground due to technical problems. Therefore no further direct comparison of the two systems was possible. The present article analyzes the flight measurements during the first experimental phase, any further analysis of later flights on 18 June will be published elsewhere.

\subsubsection{Vertical soundings}

The evolution of vertical profiles of temperature, moisture, and wind speed (Figs. 3-5) in the morning of 18 June started with a neutrally stratified, turbulent $\mathrm{ABL}$ and a capping inversion at $z_{i} \approx 600 \mathrm{~m}$ asl around 7 UTC. Directly below the inversion a humid layer was associated with Cumulus clouds in agreement with the direct
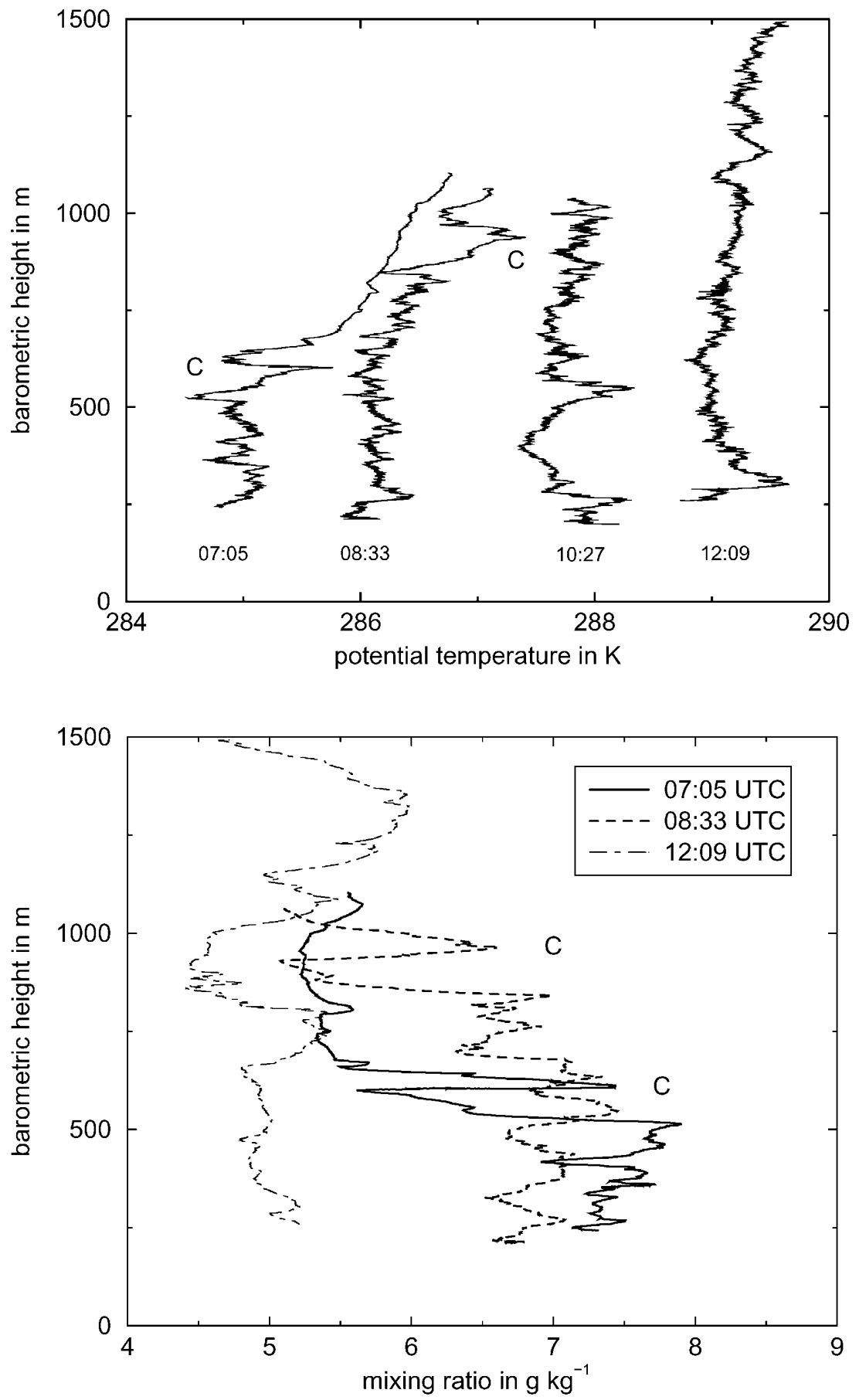

Fig. 3. Vertical profiles of potential temperature measured by Do 128 show the development of the ABL. The numbers below the profiles indicate the start time in UTC, 'C' marks the observation of Cumulus clouds
Fig. 4. Vertical profiles of mixing ratio measured by Do 128. For better differentiation, $2 \mathrm{~g} \mathrm{~kg}^{-1}$ was added to the curve measured at 8:33 UTC. 'C' marks the observation of Cumulus clouds 


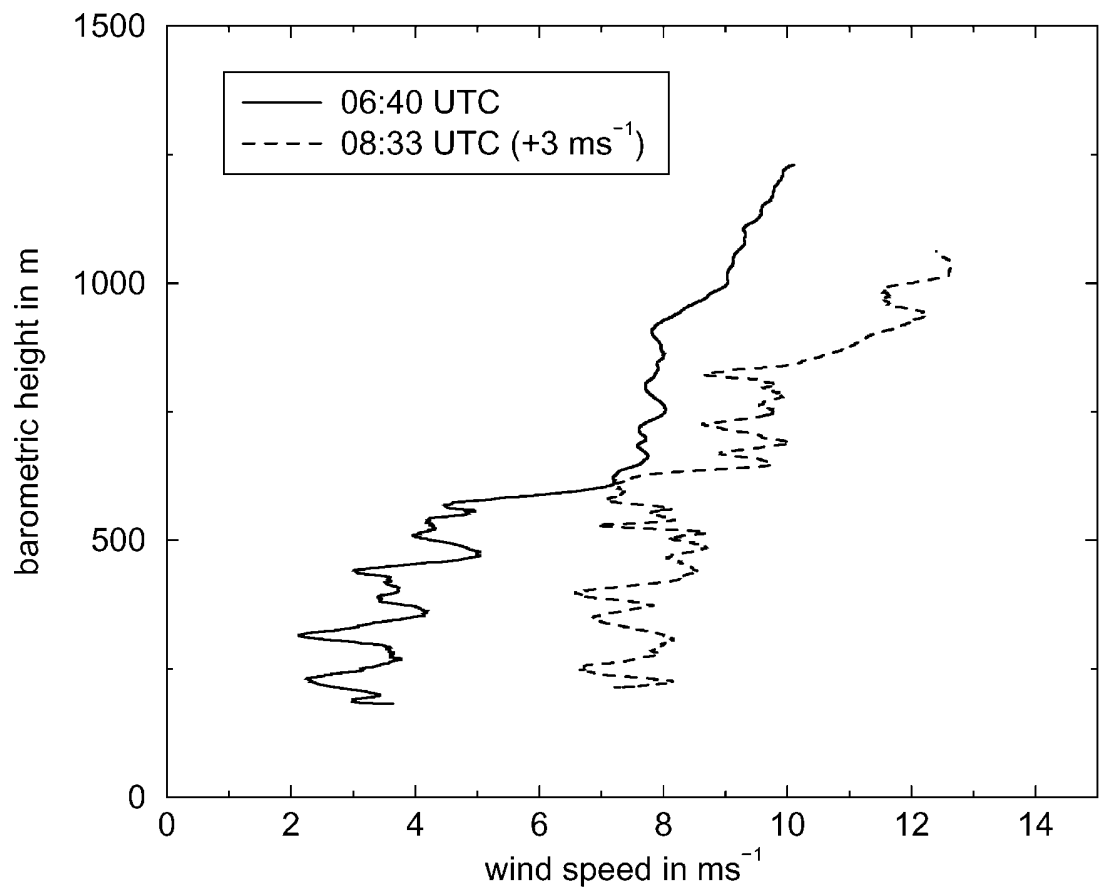

Fig. 5. Vertical profiles of wind speed measured by Do 128. For better differentiation, $3 \mathrm{~ms}^{-1}$ was added to the curve measured at 8:33 UTC observations (Section 3.2). At the same height and time the temperature profile showed a sharp local maximum. At the end of the flights, around 8:30 UTC, the ABL top grew to about $840 \mathrm{~m}$ asl with clouds at $970 \mathrm{~m}$ at 8:30 UTC. Around 10:30 UTC the ABL top was found above $1000 \mathrm{~m}$ asl, and above $1500 \mathrm{~m}$ at 12:00 UTC.

Figure 6 displays the periods of the horizontal flights versus height, together with the $\mathrm{ABL}$ height as observed during vertical aircraft soundings (crosses) and derived from windprofiler/RASS data. The aircraft observations of the ABL top were linearly interpolated. Until 8 UTC the result (dashed line) was in good agreement with the windprofiler/RASS data, although the latter showed strong fluctuations of the ABL height. At 8 UTC the ABL top - as observed by windprofiler/RASS - increased more than $200 \mathrm{~m}$

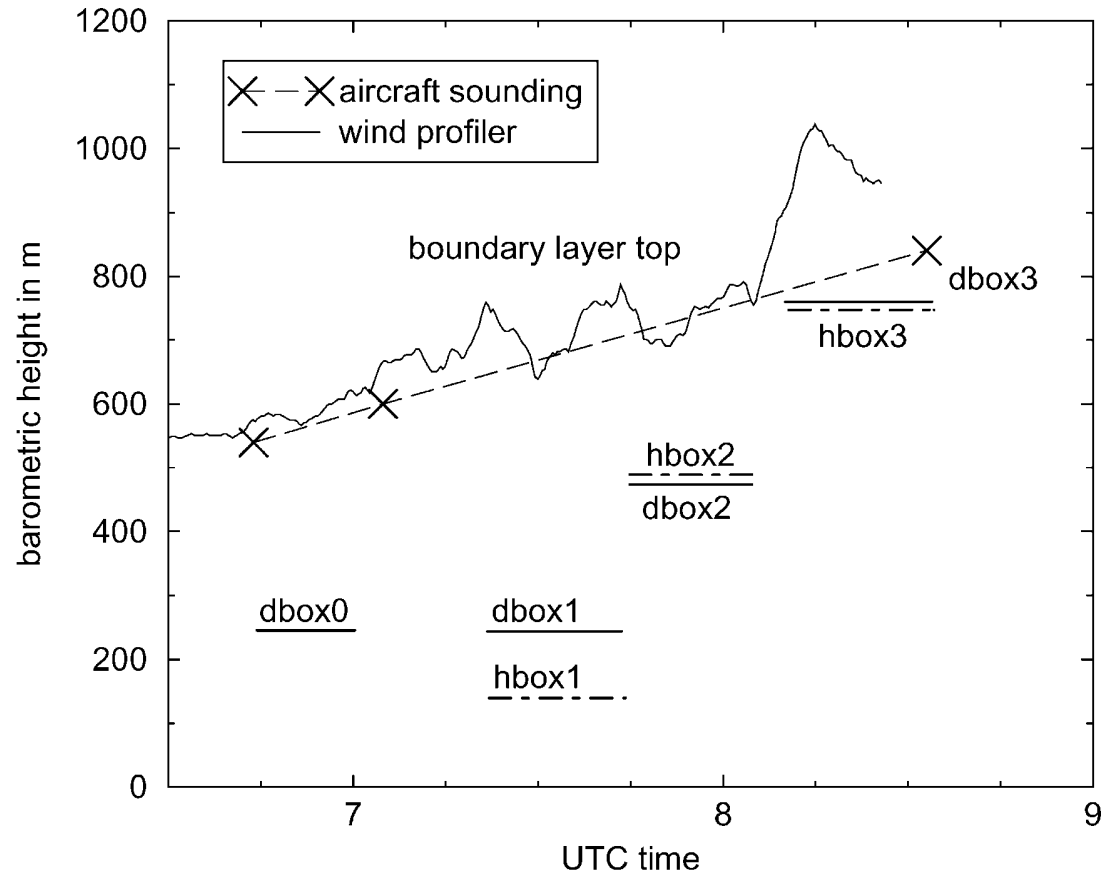

Fig. 6. Measurement flights on morning of 18 June 1998: Short horizontal lines indicate the periods of the individual box flights (solid horizontal line: Do 128, dot-dashed horizontal line: Helipod), the long dashed line represents boundary layer height interpolated from vertical aircraft soundings (crosses). The solid curve represents the ABL height measured by the windprofiler/RASS system 
within 15 minutes. This was probably a single, short-time event above the wind profiler. According to aircraft vertical soundings, the ABL continued its linear growth. All flights were carried out within the turbulent, convective, and moist boundary layer. Note that the beginning of the highest box ('hbox3' and 'dbox3') was very close to the capping inversion.

\subsection{Calculation of fluxes and their errors}

\subsubsection{Mean vertical flux}

The vertical kinematic flux $F$ along a flight leg of duration $L$ at height $z$ is defined by

$F=\left\langle w^{\prime}(t) \cdot s(t)^{\prime}\right\rangle_{L}$

with the vertical wind speed $w$ and the transported turbulent quantity $s$ (e.g., temperature, humidity, or horizontal wind speed). The prime denotes that the mean value and also the linear trend were removed from time series $w(t)$ and $s(t)$. The brackets $\langle\ldots\rangle_{L}$ indicate the time average over one flight leg of duration $L$. The mean vertical turbulent fluxes analyzed in this article are the heat flux $H$ (with potential temperature $\theta$ and specific heat of air $\left.c_{p}=1005 \mathrm{~J}(\mathrm{~kg} \mathrm{~K})^{-1}\right)$

$H=\rho c_{p}\left\langle w^{\prime} \theta^{\prime}\right\rangle$,

the latent heat flux $V$ (with mixing ratio $m$ and specific latent heat of condensation $l_{v}=$ $\left.2.5 \cdot 10^{6} \mathrm{~J} \mathrm{~kg}^{-1}\right)$

$V=\rho l_{v}\left\langle w^{\prime} m^{\prime}\right\rangle$,

and the vertical flux of horizontal momentum $\tau$

$\tau=\rho \sqrt{\left\langle w^{\prime} u^{\prime}\right\rangle^{2}+\left\langle w^{\prime} v^{\prime}\right\rangle^{2}}$

with the horizontal wind components $u$ and $v$. The air density $\rho$ at height $z$ was calculated using the approximation for ideal gas

$\rho(z)=\frac{\bar{p}(z)}{R_{L} \bar{T}(z)}$

with $R_{L}=287 \mathrm{~m}^{2} \mathrm{~s}^{-2} \mathrm{~K}^{-1}$, mean temperature $\bar{T}$, and mean air pressure $\bar{p}$.

\subsubsection{Statistical error of flux}

Based on Lumley and Panofsky (1964), and Lenschow and Stankov (1986), Lenschow et al. (1994) explained how to differentiate the systematic statistical error $\Delta F$ of a flux $F$ from its random error $\sigma_{F}$.

\section{Systematic error}

A measured flux $F$ as defined in (1) is only an estimation of the ensemble averaged flux $F_{E}$, which can be seen as the average of all time means of $w^{\prime} s^{\prime}$ or as the result of infinite averaging over time (Lumley and Panofsky, 1964; Lenschow et al., 1994) in a way that

$\lim _{L \rightarrow \infty} F=F_{E}$,

if assuming ergodic and therefore stationary time series. The absolute deviation of the flux $F$ from its unknown ensemble average

$\Delta F=\left|F_{E}-F\right|$

defines the systematic statistical error of $F$. The systematic error can be estimated by a simple expression

$\Delta F \approx 2 \cdot \frac{I_{w s}}{L} \cdot F$

as long as the averaging time $L$ is large compared to the integral time scale of the flux

$I_{w s}=\frac{1}{F} \int_{0} d t \operatorname{Cov}_{w s}(t)$

which is identical to the integral of the covariance function $\operatorname{Cov}_{w s}$ normalized to unity at lag $t=0$.

In practice, the integral scale of the flux is difficult to determine. Often $\operatorname{Cov}_{w s}$ behaves 'wild' (e.g., Mann and Lenschow, 1994). Therefore Lenschow et al. (1994) defined an upper limit of $I_{w s}$ :

$I_{w s} \leq \frac{\sqrt{I_{w} \cdot I_{s}}}{r_{w s}}$,

with correlation coefficient

$r_{w s}=\frac{F}{\sigma_{w} \cdot \sigma_{s}}$,

the integral time scale of $s$ (and $w$, respectively)

$I_{s}=\int_{0} d t \frac{\operatorname{Cov}_{s}(t)}{\sigma_{s}^{2}}$,

and their standard deviations $\sigma_{s}$ and $\sigma_{w}$.

Alternatively the integral scale can be calculated by taking advantage of the covariance theorem (e.g., Lenschow and Stankov, 1986; Mann and Lenschow, 1994). In our analysis we calculated the integral scale directly without the use of Fourier transformation to avoid systematic errors caused by two FFT's and data windows. With 
modern computers this is no longer a time-consuming problem. The integration in (12) was performed from $t=0$ until the first zero crossing of $\mathrm{Cov}_{s}$.

Finally, the upper limit of the systematic statistical error is

$\Delta F \leq \frac{2}{r_{w s}} \cdot \frac{\sqrt{I_{w} I_{s}}}{L} \cdot F$.

\section{Random error}

According to Lenschow and Stankov (1986), the random statistical error $\sigma_{F}$ of the averaged flux $F$ is the standard deviation of the time series of the kinematic flux $f(t)=w^{\prime} s^{\prime}$ :

$\sigma_{F}^{2}=\left\langle\left(f-\langle f\rangle_{L}\right)^{2}\right\rangle_{L}=\left\langle w^{\prime 2} s^{\prime 2}\right\rangle_{L}-F^{2}$,

since $\langle f\rangle_{L}=F$.

Assuming again that $I_{w s} \ll L$ and a Gaussian distribution of $w$ and $s$, the random scatter of the flux is approximated by (Lenschow and Stankov, 1986):

$\sigma_{F}^{2} \approx 2\left(1+\frac{1}{r_{w s}^{2}}\right) \cdot \frac{I_{w s}}{L} \cdot F^{2}$

Following Lenschow et al. (1994), the upper limit of the standard deviation of the measured flux is

$\sigma_{F} \leq \frac{2}{r_{w s}} \cdot \sqrt{\frac{\min \left(I_{w}, I_{s}\right)}{L}} \cdot|F|$,

which obviously contains a smaller estimate of $I_{w s}$ than defined in (10), and therefore gives a smaller random error. The use of two different estimates of $I_{w s}$ for systematic and random statistical errors was not realized by the authors. In order to avoid an underestimation of the random error, the random scatter of flux was not calculated using (16), but the estimate of (10) was also inserted into (15).

The ratio of systematic statistical error and random scatter of the flux decreases slowly towards zero for large averaging time or measurement duration $L$ :

$\frac{\Delta F}{\sigma_{F}} \sim \frac{1}{\sqrt{L}}$.

\subsubsection{Statistical error of momentum flux}

Since the vertical flux of horizontal momentum $\tau$ consists of two components

$\tau_{1}=-\rho\left\langle w^{\prime} u^{\prime}\right\rangle$ and $\tau_{2}=-\rho\left\langle w^{\prime} v^{\prime}\right\rangle$, $\tau=\sqrt{\tau_{1}^{2}+\tau_{2}^{2}}$,

the calculation of its statistical errors requires more effort: The systematic error is determined through the maximum error of $\tau$ :

$\Delta \tau=\sum_{1}^{2}\left|\frac{\partial \tau}{\partial \tau_{i}} \cdot \Delta \tau_{i}\right|=\sum_{1}^{2}\left|\frac{\tau_{i}}{\tau} \cdot \Delta \tau_{i}\right|$,

while the standard deviation of $\tau$ is obtained using Gaussian error propagation:

$\sigma_{\tau}^{2}=\sum_{1}^{2}\left(\frac{\partial \tau}{\partial \tau_{i}} \cdot \sigma_{\tau_{i}}\right)^{2}=\sum_{1}^{2}\left(\frac{\tau_{i}}{\tau} \cdot \sigma_{\tau_{i}}\right)^{2}$.

\subsubsection{Area-averaged flux}

The mean flux in (1) was determined by averaging one flight leg of continuous data. To obtain the area mean $\bar{F}$, the leg-averaged fluxes $F_{i}$ $(i=1 \ldots 4)$ of the same horizontal flight pattern at the altitude $z$ were averaged. The statistical error of $\bar{F}$ is defined by a Gaussian error reproduction, i.e., for random errors:

$\sigma_{\bar{F}}=\frac{1}{N} \sqrt{\sum_{1}^{N} \sigma_{F_{i}}^{2}}$,

with a number of four legs $(N=4)$ per horizontal flight pattern.

\section{Results and discussion}

\subsection{Scaling of the $A B L$}

To take the temporal development of the ABL into account, the fluxes were plotted against a normalized altitude axis using the Deardorff scaling $z z_{i}^{-1}$ (Deardorff, 1970). The ABL top $z_{i}$ as a function of time was derived from the vertical aircraft and Helipod soundings and interpolated linearly as shown in Fig. 6. For the evaluation of the ground-based measurements a mean ABL height of $735 \mathrm{~m}$ (asl) between 7:30 and 8:30 UTC was assumed. Before scaling, all altitude values $z$ (flight levels, tower stations, remote sensing, $z_{i}$ ) were related to ground level, taking the mean elevation of the area $(60 \mathrm{~m}$ asl) into account.

\subsection{Co-spectra}

The spectral distribution of the sensible and latent heat flux is represented by the co-spectra 
of the vertical wind $w$ with the temperature $\theta$ and the humidity $m$, respectively. Co-spectra display the range of turbulence scales that were resolved by the measurements. Furthermore the spectral analysis helps to identify systematic measurement errors. The co-spectrum of e.g., the vertical wind and the potential temperature, is defined as the real part of the cross-spectrum XS,

$$
\begin{aligned}
\mathrm{CS}_{w \theta}(f) & =\Re\left[\mathrm{XS}_{w \theta}(f)\right] \\
& =\int d t \operatorname{Cov}_{w \theta}(t) \cos (2 \pi f t),
\end{aligned}
$$

and can be calculated using the fast Fourier transformation,

$\mathrm{CS}_{w \theta}(f)=\frac{1}{L} \cdot \Re\left[\tilde{w}^{*}(f) \cdot \tilde{\theta}(f)\right]$,

with the Fourier-transformed vertical wind $\tilde{w}^{*}$ (complex-conjugate) and potential temperature $\tilde{\theta}$. To smooth the spectral-density curves and to make them spatially representative, the co-spectra of all four legs flown at an identical height were averaged (Figs. 10 and 11).

The mean co-spectrum of 'dbox1' (lower chart in Fig. 10) exhibited a large local maximum at about $0.045 \mathrm{~Hz}$ which was also found in the cospectrum of $w$ and $m$. The peak was significant with a probability larger than 95\% (assuming a Laplace distribution) and was most likely caused by the phygoide of the Do 128 . The phygoide is a damped, slow harmonic oscillation of air speed and altitude caused by the flight-mechanical transfer of kinetic to potential energy and vice versa. Its frequency can be roughly estimated by (Brockhaus, 1994)

$f_{p}=\frac{1}{\sqrt{2} \cdot \pi} \cdot \frac{g}{v_{0}}$

with the air speed $v_{0}$ and the acceleration $g$ due to gravity. Since the vertical wind, the mixing ratio, and the temperature depend on the height, the phygoide causes a systematic error. Its contribution to the flux cannot easily be corrected but is localized to a narrow frequency band and therefore entails only a small flux error. A period of 20 to $30 \mathrm{~s}$ is quite typical for an airplane at $60 \mathrm{~ms}^{-1}$ air speed. Since the phygoide is caused by steering motions (in particular by the elevation control) its existence depends on the reaction of the pilot to convection or after turning. Normally the phygoide is avoided by pilots on meteorological measurement flights. Hence the other spectra measured by the airplane show related maxima, but with smaller amplitude. A similar systematic measurement error caused by Helipod's pendulum oscillations (Bange and Roth, 1999) could not be identified in the data presented here. This is because the effect is small and the background of atmospheric turbulence was large.

Significant turbulent transport commenced at about $0.5 \mathrm{~Hz}$ or $100 \mathrm{~m}$ wavelength at all flight levels. Since both airborne systems sampled at much higher frequency, all contributions to smallscale turbulent transport were fully recorded. The transport then increased towards larger scales, reaching a broad and diffuse maximum. Generally, the far left hand side of the spectra was not significant because the density of data decreased rapidly.

At low altitude (140 and $245 \mathrm{~m})$ the spectral density reached almost zero at about $0.03 \mathrm{~Hz}$ or a length between 1300 and $2000 \mathrm{~m}$, which exceeded the ABL height by a factor of 2 to 4 . This gap probably separated turbulent transport and random contributions to the spectra. The gap was not visible at middle and high altitudes due to larger eddies and convective elements mixing with random contributions.

To enhance the accuracy of large scale measurements i.e., to reduce the statistically random and systematic errors, longer flights over larger distances are necessary. This can cause a problem with the non-stationarity of the ABL. Furthermore, the flight experiment was restricted to the LITFASS area in order to allow comparison of both flight and ground-based measurements. To see whether the flight distances were long enough to achieve correct values and acceptable statistical uncertainties, the area-averaged fluxes and their statistical uncertainties were calculated for the airborne systems and compared to the ground-based measurements.

\subsection{Influence of surface heterogeneity}

Flight measurements were performed over a heterogeneous landscape, though the size of some homogeneous surface patches (like forest or lakes) was large enough that their influence could be observed during low-level flights, taking into account the western wind. Of course the influence 
of local surface characteristics was largest on the lowest flights which were carried out with the Helipod at about $80 \mathrm{~m}$ agl (hbox1). A dependence on the location of the legs was not observed during the lowest Do 128 at about $200 \mathrm{~m}$ altitude. In particular the western leg was dominated by forest, followed by the southern leg, which had also a section of open water (Fig. 2 in Beyrich et al., 2002b). The northern leg was mostly located leeward of the large lake Scharmützelsee, while the flight on the eastern leg was influenced by nearly all surface types within the investigation area.

The turbulent fluxes above the most widespread surface types (grass, barley, triticale, water, and forest) were measured with micrometeorological ground stations. As expected, momentum and sensible heat flux were largest above forest, mainly due to greater heating over the forest and its large surface roughness (Mahrt and Ek, 1993).

The sensible heat flux above forest was larger by a factor of two compared to all other surface types (Figs. 7 and 9). Consequently, the largest fluxes of sensible heat and momentum were measured by the Helipod on the western leg, followed by the southern leg. The smallest fluxes of momentum and heat were observed above water - the surface with the lowest roughness

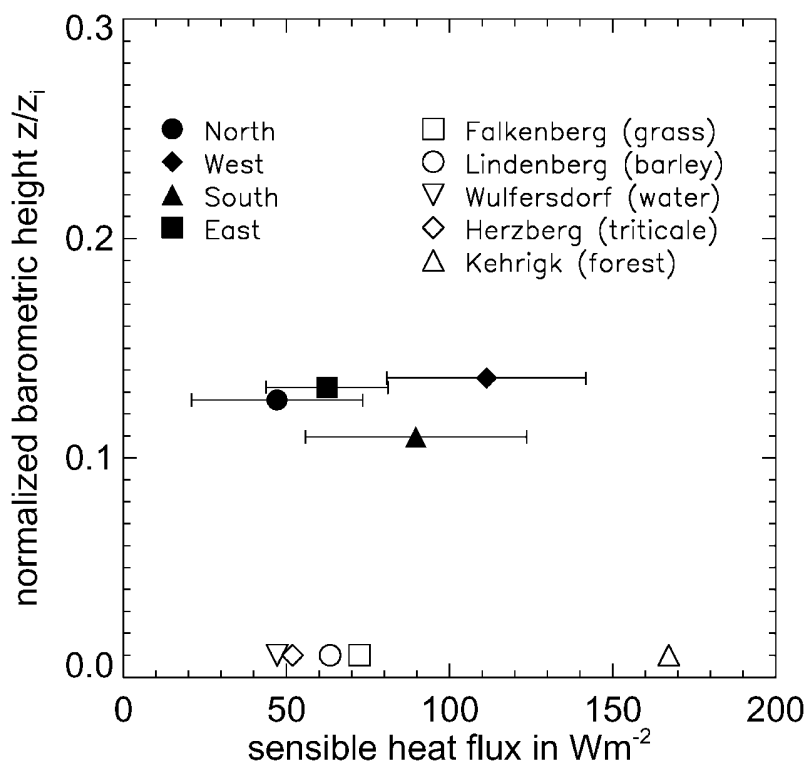

Fig. 7. Leg-averaged sensible heat flux $H$ in Deardorff scaling measured on the lowest Helipod flight ('hbox1'). Filled symbols indicate Helipod measurements sorted by leg location. Empty symbols indicate ground-based measurement above different surface types

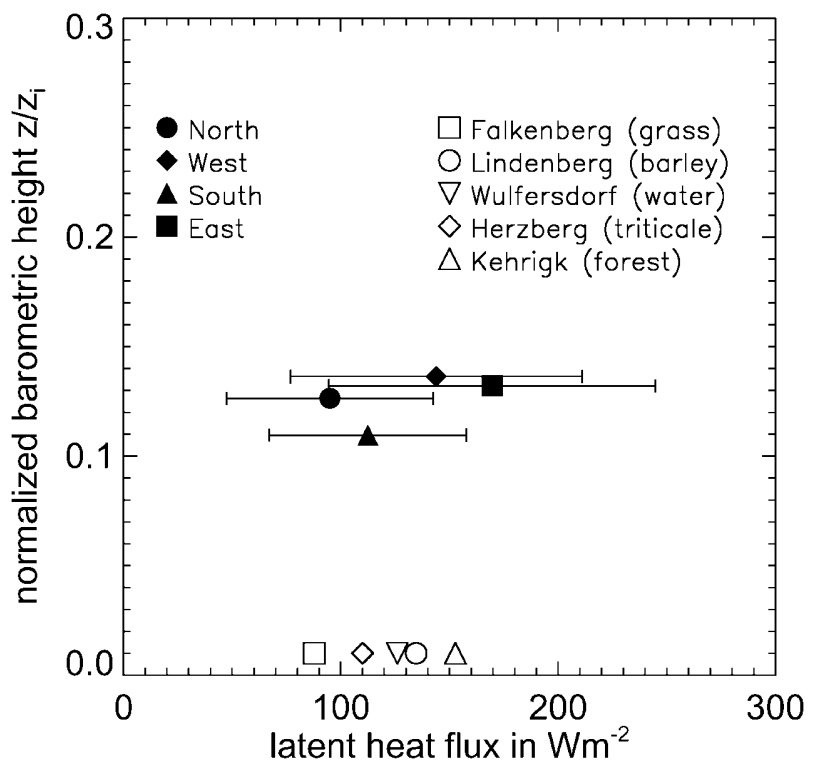

Fig. 8. Leg-averaged latent heat flux $V$ measured on the lowest Helipod flight ('hbox1'). For explanation of symbols see Fig. 7

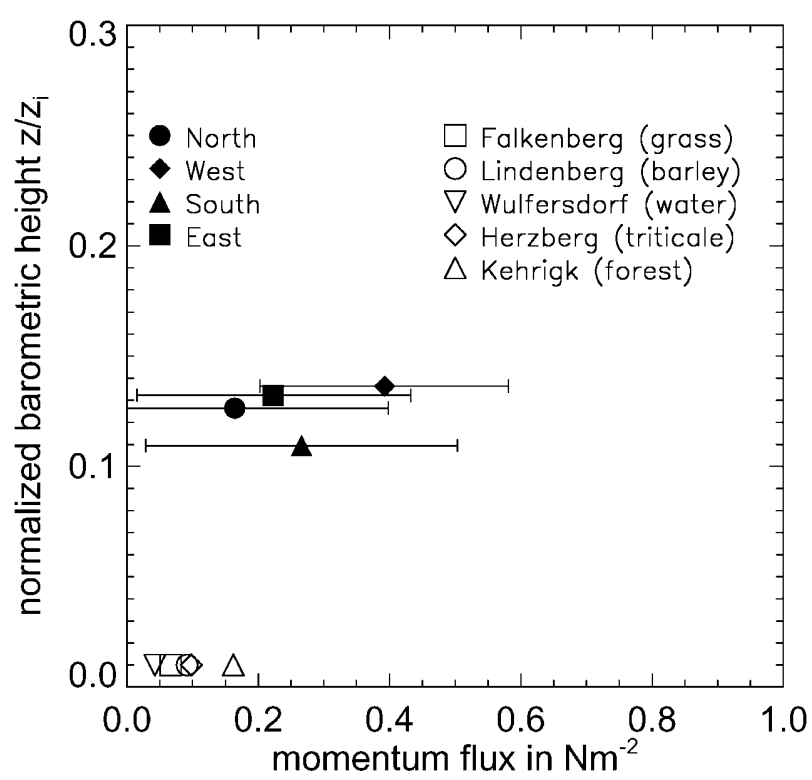

Fig. 9. Leg-averaged momentum flux $\tau$ measured on the lowest Helipod flight ('hbox1'). For explanation of symbols see Fig. 7

and temperature, and therefore the Helipod flight detected the smallest fluxes on the northern leg.

While the flight measurements matched the observations at the ground stations regarding the fluxes of sensible heat and momentum, the airborne-observed distribution of latent heat flux (Fig. 8) did not agree with the ground-based measurements. The largest humidity flux was found 

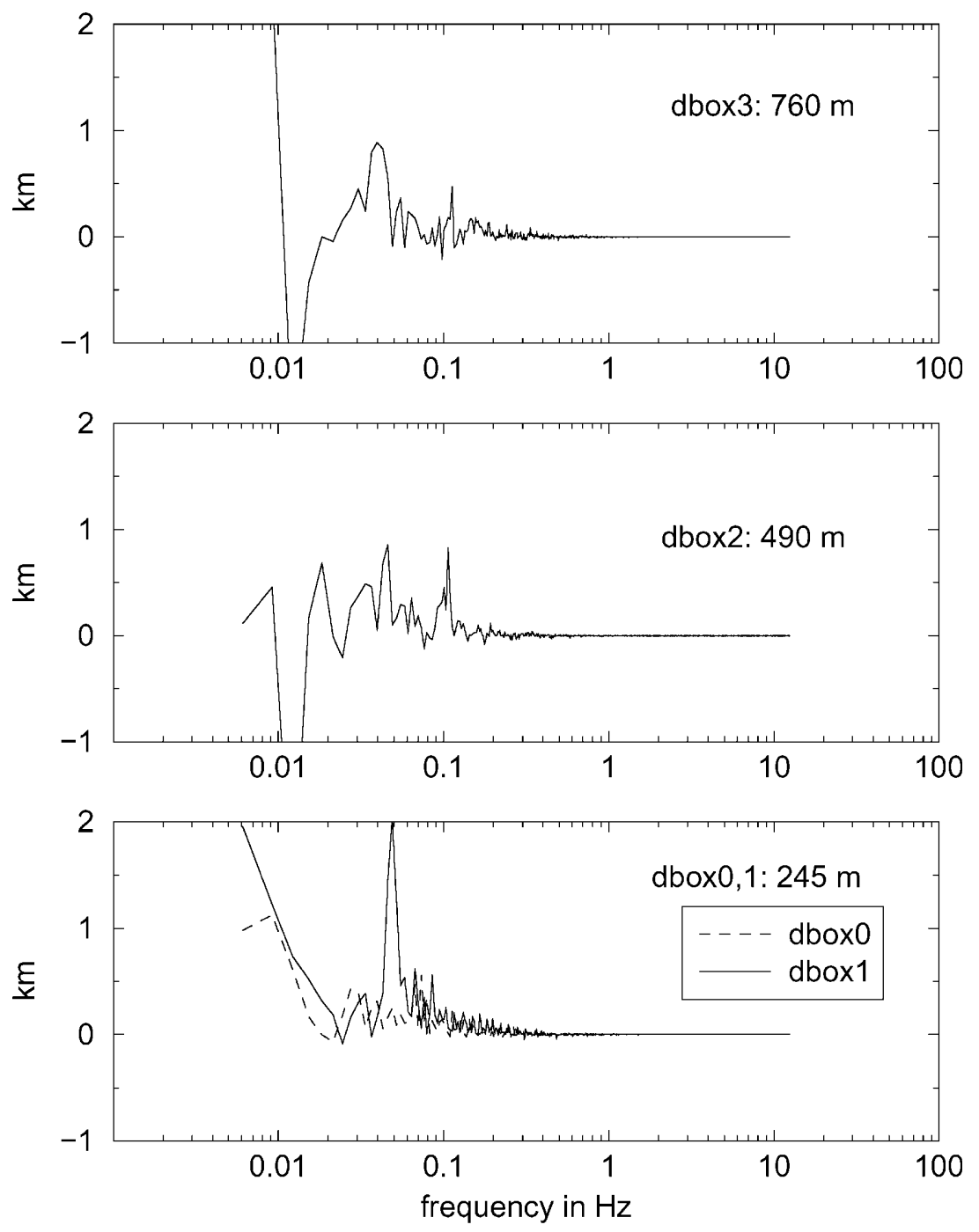

Fig. 10. Co-spectra of $w$ and $\theta$ measured by Do 128 at three different heights. In order to smooth the curves, the data was averaged over four legs above forest (and not above the water surface, which lacked surface roughness to produce sufficient turbulence), and the smallest above grass. No connection to the airborne measurements was found, although the magnitude of the observed fluxes, at the surface and at $80 \mathrm{~m}$ height, were similar. It seems that the Helipod observations were decoupled from the distribution of surface types, or in other words, that the surface distribution of latent heat flux did not affect the flux measurements at $80 \mathrm{~m}$ height. An explanation for this observation will be given in the discussion.

\subsection{Area-averaged fluxes}

4.4.1 Statistical errors and general observations

On all flight legs the systematic statistical error $\Delta F$ (Eq. 7) was one order of magnitude smaller than the random error $\sigma_{F}$ (Eq. 14) and could be disregarded. After averaging the fluxes that were measured at identical height over all four flight legs, the statistical uncertainties represented by the error bars in Figs. 12 to 14 were reduced by a factor of two. Since the statistical error was a function of the time $L$ needed for one leg, the results from the Do 128 measurements had a smaller statistical error than the Helipod results at the same altitude. The standard deviation of altitude was about $8 \mathrm{~m}$ (Helipod) and $3 \mathrm{~m}$ (Do 128) on all legs, and therefore smaller than the height of the symbols used in plotting the flux.

The statistical uncertainties associated with the fluxes were largest at the top of the ABL. The flights were sometimes below and sometimes above the capping inversion (see Fig. 6). In addition, the heterogeneity of the upper ABL was 

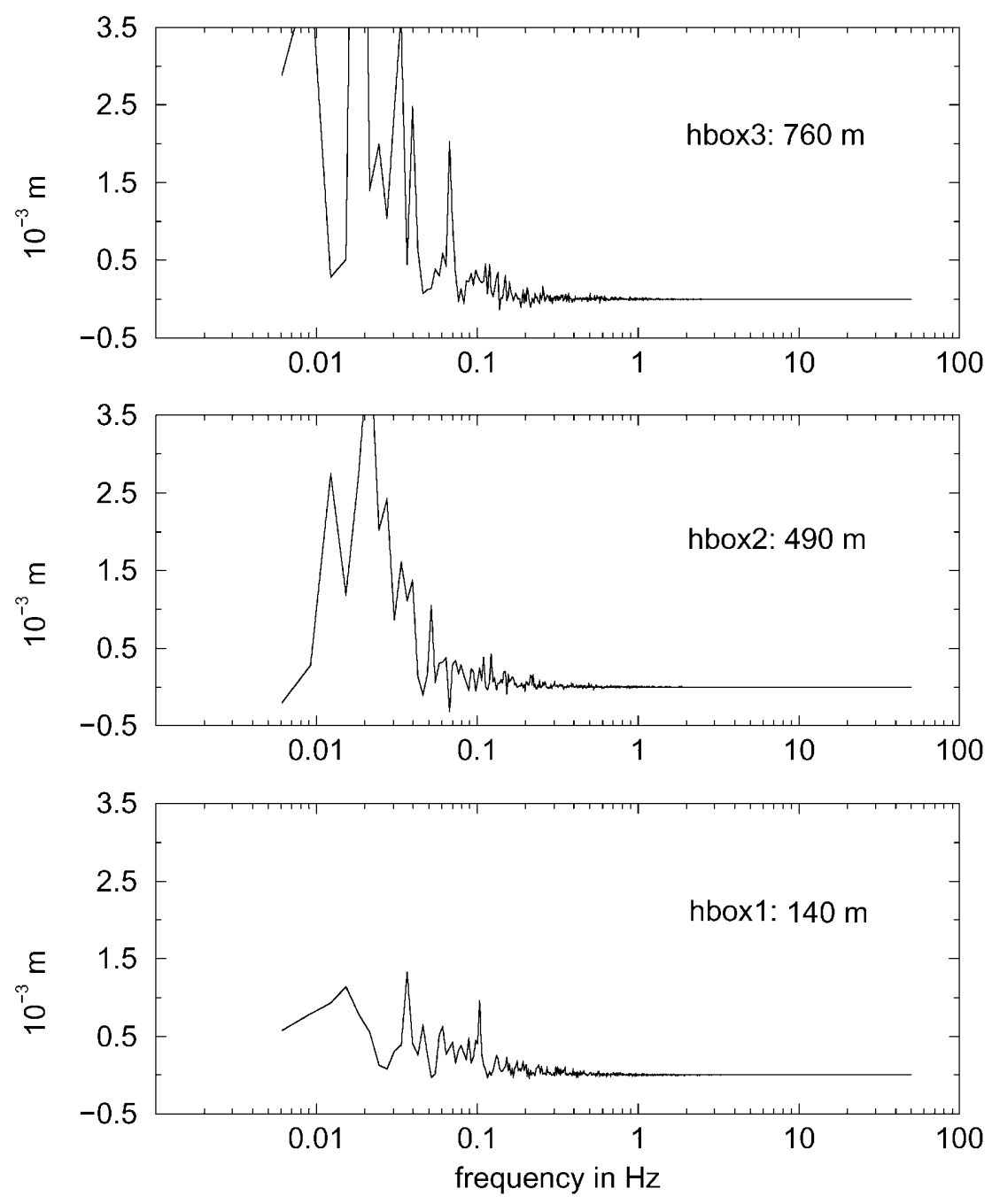

Fig. 11. Mean co-spectra of $w$ and $m$ measured by Helipod

enhanced by the patchy pattern of Cumulus clouds.

The area-averaged fluxes measured simultaneously by the Helipod and the Do 128 (Figs. 12 to 14) in the middle and at the top of the ABL ('box2' and 'box3') were in very good agreement. The difference between the Helipod and the Do 128 measurements was much smaller than the statistical error.

The mean fluxes measured on the last leg of 'dbox0' (i.e., the eastern leg) were about two times larger than the fluxes on the three previous legs. The fluxes measured on the last leg of 'dbox0' and on the entire following flight 'dbox1' were, however, of similar magnitude. At the beginning of the experiment the fluxes in the ABL did not increase linearly with time, but showed a steep increase around 7:00 UTC at the end of the first low-level flight. This non-linear time-dependence was not compensated by the
Deardorff scaling. Therefore the data of 'dbox0' were not used for area-averaged fluxes.

\subsubsection{Ground-based measurements}

Where available, ground-based measurements were added to the flux profiles. To calculate area-representative values, the results from micro-meteorological ground stations were averaged, corresponding to their share in the entire area (i.e., $45 \%$ forest, $7 \%$ water, and $16 \%$ triticale, barley, and grass, each). The scintillometer recorded turbulent characteristics of different surface types along a path of $4.7 \mathrm{~km}$ length.

Due to a western wind the upper two stations of the $99 \mathrm{~m}$ tower did not represent the immediate surroundings of the tower (i.e. grassland). Enhanced values of the momentum and sensible heat flux at the upper levels reflected a higher surface roughness in the corresponding footprint 


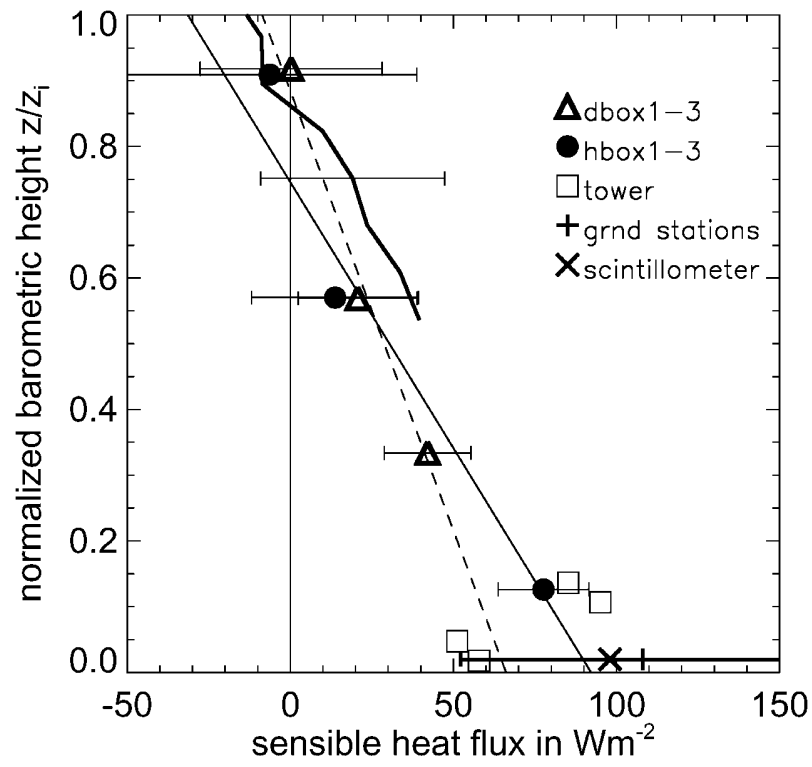

Fig. 12. Profile of area-averaged sensible heat flux $H$. Filled circles indicate Helipod measurements, triangles Do 128 flights. The straight lines represent the linear regression of the flight data (Helipod - solid line; Do 128 - dashed line). The regression was weighted by the standard deviations of the airborne-measured fluxes (error bars). The curve in the upper half represents heat flux measured by the windprofiler/RASS system, with one exemplary error bar. Furthermore, ground-based measurements are represented by boxes (tower), cross (scintillometer), and plus sign (averaged micro-meteorological stations; the error bar indicates the variability between the different sites)

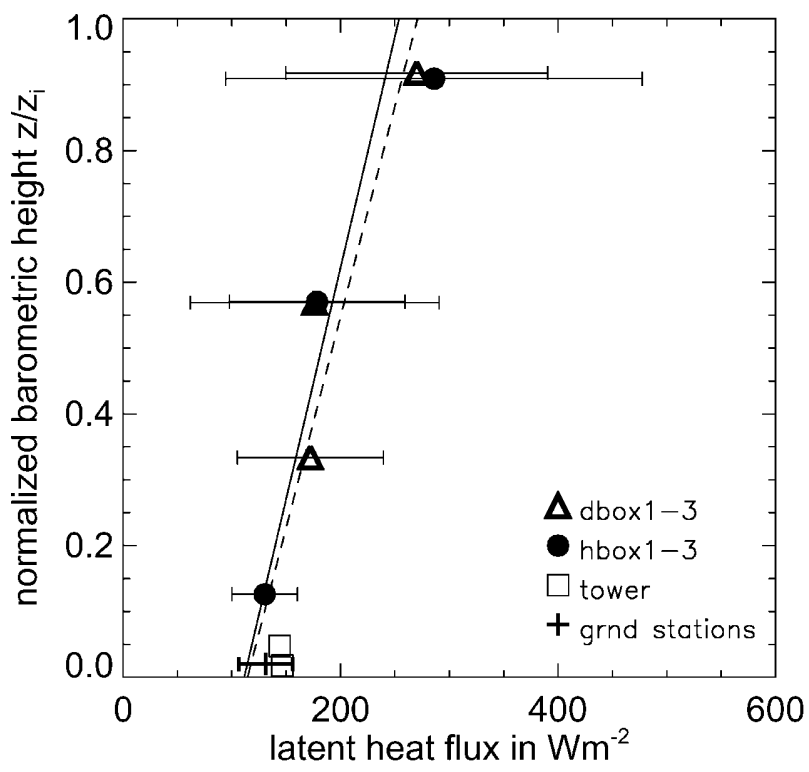

Fig. 13. Profile of area-averaged latent heat flux $V$. For explanation of symbols see Fig. 12

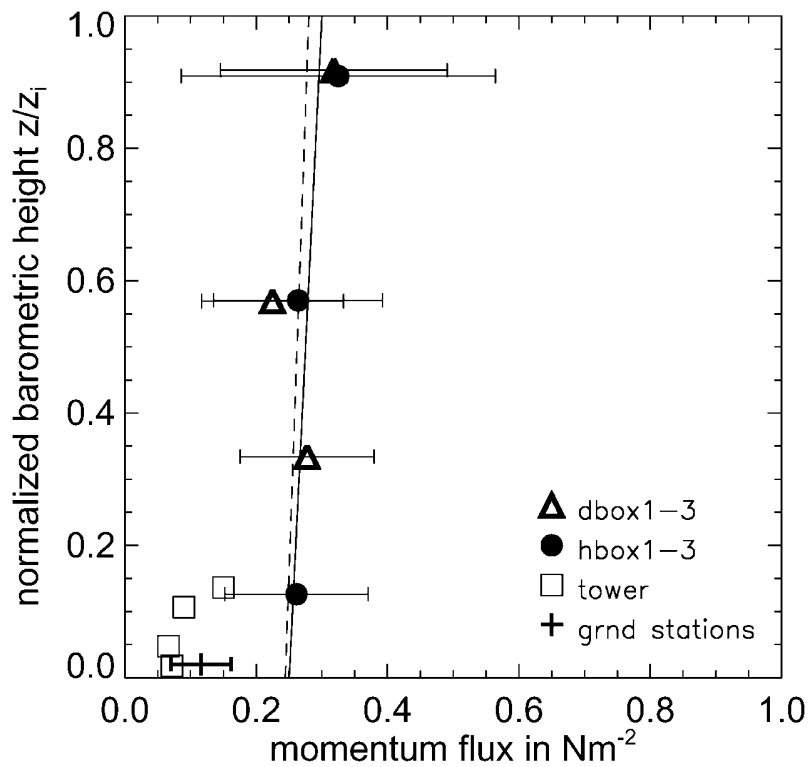

Fig. 14. Profile of area-averaged momentum flux $\tau$. For explanation of symbols see Fig. 12

areas (Beyrich et al., 2002a). The highest tower measurements and the lowest Helipod flight were performed at about the same altitude and led to similar results (Figs. 12 and 13).

\subsubsection{Sensible heat flux}

In agreement with the ABL theory, the airbornemeasurement of sensible heat flux profiles were linearly extrapolated to the ground (Fig. 12). The extrapolation of the Helipod measurements met the averaged ground-station and scintillometer measurements very well. The extrapolation of the Do 128 measurements led to smaller fluxes within the scatter bars of the ground-station measurements that met the observations of the two lower tower stations. The windprofiler/RASS measurements (solid curve) were in agreement with the airborne observations in the upper ABL. Unfortunately with the windprofiler/RASS RASS it was not possible to observe the lower half of the ABL due to ground-clutter influence.

\subsubsection{Latent heat flux}

Although there are no clear concepts for the vertical profile of latent heat flux in a cloudy and convective ABL (see Chapters 2.7 and 13.4 in Stull, 1988) a linear fit was a good approximation of the corresponding airborne measurements (Fig. 13). The linear extrapolation of latent heat fluxes to the ground, measured simultaneously by 
the Helipod and the Do 128, the averaged groundstation measurements, and the tower observations all produced almost identical surface fluxes.

\subsubsection{Momentum flux}

The profiles of the momentum flux derived from the Helipod and Do 128 measurements were almost identical (Fig. 14). The observations from the $99 \mathrm{~m}$ tower suggested a non-linear flux profile close to the ground. Thus the ground-based measurements showed considerably smaller surface fluxes of momentum than the extrapolated flight measurements. Above the surface layer, a heightindependent momentum flux gave probably the best approximation of the airborne measurements.

\section{Summary and conclusions}

Simultaneous flight measurements over heterogeneous terrain with two different systems were performed on 3D-box-flight patterns in a convectively driven ABL. Two different pattern sizes were used: $10 \mathrm{~km} \times 10 \mathrm{~km}$ for the Helipod and $15 \mathrm{~km} \times 15 \mathrm{~km}$ for the Do 128 flights. Co-spectra-analysis showed that the small-scale turbulent transport was completely sampled by both systems. The phygoide of the airplane could be identified as a significant peak in some co-spectra - and as far as the authors are aware - this is the first time this has been observed in meteorological flight measurements. The largest energy-transporting eddies in the ABL were about $1000 \mathrm{~m}$ to $2000 \mathrm{~m}$ in size, depending on height. Since large eddies and convective elements mixed with random contributions at the large-scale end of the spectra, significant sampling of large-scale turbulence was uncertain. To solve the uncertainty a direct comparison of airborne, remotely sensed, and ground-based measurements was carried out.

Vertical fluxes of momentum, sensible, and latent heat flux were calculated for each individual flight leg, as well as their statistical errors, using a variation of the method described by Lenschow et al. (1994). On all flights the systematic statistical error $\Delta F$ was one order of magnitude smaller than the random statistical error $\sigma_{F}$. The standard deviation $\sigma_{F}$ of fluxes measured by the Do 128 was generally smaller than the corresponding error of the Helipod measurements at identical height because the Do 128 flew longer distances. Due to variable ABL height and a patchy pattern of Cumulus clouds, the statistical error was largest at the top of the ABL. The absolute uncertainty of the latent heat flux was about three times larger than the statistical error of the sensible heat flux at each altitude. The simultaneous measurements of all three fluxes performed by the Helipod and the Do 128 at identical height were in very good agreement. The difference between the Helipod and the Do 128 measurements was much smaller than the corresponding statistical uncertainties. This suggests that the statistical errors of the flight measurements were over-estimated.

The sensible heat flux derived from the windprofiler/RASS data was in good agreement with the airborne measurements, although a comparison was only possible in the upper half of the ABL. The linear extrapolation of the simultaneous airborne measurements was in good agreement with the ground-based observations (averaged measurements from micro-meteorological stations on different surface types, scintillometer and tower measurements) of latent and sensible heat.

A linear fit was the best approximation of all three flux profiles. The momentum flux was nearly constant above the surface layer. Close to the ground a non-linear increase of momentum flux was observed by the tower. Therefore, the linear extrapolation of airborne measurements could not meet the surface flux. The latent heat flux observed with both airborne systems increased linearly with height. Although the corresponding statistical uncertainties also increased, the mean fluxes calculated from Helipod and Do 128 flights were nearly identical. This led to the conclusion that the interpolated profile in Fig. 13 was realistic. Additionally, similar profiles of latent heat under convectional conditions were also described in the literature (e.g. Stull, 1988).

The comparison of low-level Helipod flights $(80 \mathrm{~m} \mathrm{agl})$ and the individual measurements of ground stations indicated that the heterogeneity of the terrain influenced the observed leg-averaged fluxes of sensible heat and momentum in the way that the measured fluxes showed a systematic dependence on the location of the flight legs. E.g., flights over forest led to large fluxes in agreement with direct measurements in the 
forest. This dependence was not observed for the airborne-detected humidity flux. The surface distribution of latent heat flux did not affect the flux measurements at $80 \mathrm{~m}$ height. This can be explained with the observed vertical flux profile.

The ABL contained humid layers and was topped by Cumulus clouds (Fig. 4). Therefore, besides evaporation at the surface there were additional sources of turbulent humidity flux within the ABL, which caused an increase of the flux with height and masked the influence of the heterogeneous surface.

The Helipod sampling on a rather small horizontal flight pattern and the Do 128 on a 1.5 times larger pattern measured nearly identical areaaveraged fluxes during LITFASS-98. Furthermore, the airborne measurements were in good agreement with windprofiler/RASS and groundbased observations. Systematic discrepancies between airborne and ground-based measurements - as reported from other experiments with other equipment - were not found here. The results show that the Helipod - designed as a small-scale turbulence probe - and the flight strategy used for this study are also well suited for moderately convective ABL.

\section{Acknowledgments}

The authors are grateful to the Institute for Flight Guidance at the Technical University of Braunschweig and Aerodata company for their technical support during the experiment. Thanks are due to Wiebke Deierling, Mikhail Strunin, and an anonymous reviewer for helpful advises on the article.

\section{References}

André J, Bougeault P, Goutorbe JP (1990) Regional estimates of heat and evaporation fluxes over non-homogeneous terrain. Examples from the HAPEX-MOBILHY programme. Bound-Layer Meteor 50: 77-108

Bange J (1997) Flugexperimente in der planetaren Grenzschicht: Numerische Simulation und erste Messungen mit der Hubschrauberschleppsonde HELIPOD in der nächtlichen Grenzschicht, volume 55. Hannover: Ber Inst f Meteorol u Klimatol, 85 pp, dissertation

Bange J, Roth R (1999) Helicopter-borne flux measurements in the nocturnal boundary layer over land - a case study. Bound-Layer Meteor 92: 295-325

Betts A, Desjardins R, MacPherson J, Kelly R (1990) Boundary-layer heat and moisture budgets from FIFE. Bound-Layer Meteor 50: 109-137

Betts A, Desjardins R, MacPherson J, Kelly R (1992) Budget analysis of the boundary layer grid flights during FIFE 1987. J Geophys Res 97: 18533-18546
Beyrich F, Berger F, de Bruin H, Foken T, Kohsiek W, Richter S, Weisensee U (2002a) Experimental determination of turbulent fluxes over the heterogeneous LITFASS area - selected results from the LITFASS-98 experiment. Theor Appl Climatol (this issue)

Beyrich F, Herzog HJ, Neisser J (2002b) The LITFASS project of DWD and the LITFASS-98 experiment: The project strategy and the experimental setup. Theor Appl Climatol (this issue)

Brinkmann J (1999) Instrumentation of the Do 128 D-IBUF for airborne measurements. In SFB 233 Abschlußband, Mainz

Brockhaus R (1994) Flugregelung. Berlin, Heidelberg: Springer, $820 \mathrm{pp}$

Claussen M (1991) Estimation of areally-averaged surface fluxes. Bound-Layer Meteor 54: 387-410

Corsmeier U, Hankers R, Wieser A (2001) Airborne turbulence measurements in the lower troposphere onboard the research aircraft Dornier 128-6, D-IBUF. Meteor Z N F 4: 315-329

Deardorff J (1970) Convective velocity and temperature scales for the unstable planetary boundary layer and for Rayleigh convection. J Atmos Sci 27: 1211-1213

Desjardins R, MacPherson J, Schuepp P, Karanja F (1989) An evaluation of aircraft flux measurements of $\mathrm{CO}_{2}$, water vapor and sensible heat. Bound-Layer Meteor 47: $55-69$

Emeis S (1995) Determination of the surface sensible heat flux from aircraft measurements. Beitr Phys Atmos 68: $143-148$

Engelbart D, Steinhagen H, Görsdorf U, Lippmann J, Neisser J (1996) A $1290 \mathrm{MHz}$ profiler with RASS for monitoring wind and temperature in the boundary layer. Beitr Phys Atmos 69: 63-80

Engelbart D, Steinhagen H, Görsdorf U, Neisser J, Kirtzel HJ, Peters G (1999) First results of measurements with a newly designed phased-array Sodar with RASS. Meteorol Atmos Phys 71: 71-68

Engelbart DAM, Bange J (2002) Determination of boundary-layer parameters using wind profiler/RASS and sodar/RASS in the frame of the LITFASS-project. Theor Appl Climatol (this issue)

Grunwald J, Kalthoff N, Corsmeier U, Fiedler F (1996) Comparison of areally averaged turbulent fluxes over nonhomogeneous terrain: Results from the EFEDA-field experiment. Bound-Layer Meteor 77: 105-134

Grunwald J, Kalthoff N, Fiedler F, Corsmeier U (1998) Application of different flight strategies to determine areally averaged turbulent fluxes. Beitr Phys Atmos 71: 283-302

Hankers R (1989) The equipment of a research aircraft with emphasis on meteorological experiments. In Soc. of Flight Test Eng., 20th Ann Symp, Reno, Nevada

Kelly RD, Smith EA, MacPherson JI (1992) A comparison of surface sensible and latent heat fluxes from aircraft and surface measurements in FIFE 1987. F Geophys Res 97: 18445-18453

Lenschow DH, Mann J, Kristensen L (1994) How long is long enough when measuring fluxes and other turbulence statistics. J Atmos Oceanic Technol 11: 661-673 
Lenschow DH, Stankov BB (1986) Length scales in the convective boundary layer. J Atmos Sci 43: 1198-1209

Lumley L, Panofsky H (1964) The structure of atmospheric turbulence. New York: John Wiley \& Sons, 239 pp

Mahrt L, Ek M (1993) Spatial variability of turbulent fluxes and roughness lengths in HAPEX-MOBILHY. BoundLayer Meteor 65: 381-400

Mann J, Lenschow D (1994) Errors in airborne flux measurements. J Geophys Res D 99: 14519-14526

Muschinski A, Frehlich R, Jensen M, Hugo R, Hoff A, Eaton F, Balsley B (2000) Fine-scale measurements of turbulence in the lower troposphere: An intercomparison between a kite- and balloon-borne, and a helicopter-borne measurement system. Bound-Layer Meteor 98: 219-250

Roth R (1999) Die Vermessung der mittleren Felder von Druck und Temperatur mit dem HELIPOD in der planetaren Grenzschicht - die Untersuchung eines Fallbeispiels. Meteor Z N F 8: 71-75

Scherf A, Roth R (1997) Estimates of area-averaged turbulent energy fluxes in a convectively driven boundary layer using aircraft measurements. Phys Chem Earth 21: 399-403

Schröter M, Bange J, Raasch S (2000) Simulated airborne flux measurements in a LES generated convective boundary layer. Bound-Layer Meteor 95: 437-456

Stull R (1988) Boundary Layer Meteorology. Dordrecht: Kluver Acad, 666 pp

Wolff M, Bange J (2000) Inverse method as an analysing tool for airborne measurements. Meteor $\mathrm{Z} \mathrm{N} \mathrm{F} \mathrm{9:}$ $361-376$

Authors' addresses: Jens Bange (e-mail: j.bange@ tu-bs.de), Technische Universität Braunschweig, Institut für Luft- und Raumfahrtsysteme, Hermann-Blenk-Strasse 23, D-38108 Braunschweig, Germany; F. Beyrich, D.A.M. Engelbart, Meteorologisches Observatorium Lindenberg, Deutscher Wetterdienst, Am Observatorium 12, OT Lindenberg, D-15848 Tauche, Germany. 